\title{
Overflow Mechanism and Demonstration of Knowledge Flow on Enterprise Endogenous Innovation by the Three-Dimensional Space: Based on the Open Innovation Perspective
}

\author{
Min Yang ${ }^{1 *}$, Jingxian Wang ${ }^{2}$ \\ ${ }^{1}$ College of Economics and Business Administration, Chongqing University, \\ Chongqing 400044, China \\ ${ }^{2}$ College of Economics, Liaoning University, Shenyang 110036, China \\ ${ }^{1}$ Yaya430411@163.com, ${ }^{2}$ Wangjingxian195612@163.com
}

\begin{abstract}
This paper made a systematic presenting for the external environment and spatial structure of enterprise innovation and defined the three-dimensional space of enterprise innovation based on the spatial economics and open innovation perspective. The 'knowledge flow' was used as an important dimension when delving into the dynamic feedback mechanism between the enterprise innovation and three-dimensional space, forming a systematic recognition for interaction mechanism of three-dimensional space, knowledge flow and the enterprise endogenous innovation. And then, a demonstration based on the structural equation model was used to provide a theoretical basis for the innovation decision of an enterprise. It followed that, the economic space, geographic space and human space all constitute the three-dimensional space of enterprise external knowledge flow. In the open innovation system, the non-rigid boundary of enterprises provides the possibility of the overflow, expansion and penetration of external knowledge. Again, through the mediation of knowledge flow, the dynamic interaction of system dynamics between the three-dimensional space and enterprise endogenous innovation was achieved.
\end{abstract}

Keywords: Open Innovation, Innovative Three-Dimensional Space, Knowledge Flow, Structural Equation Model

\section{Introduction}

The "open innovation", mainly characterized in open \& complementary and dynamic feedback, has achieved the most of heterogeneity innovation resource and knowledge scattered into the economic space and the exchange interaction of external knowledge inside of the organization. The 'ownerless knowledge', being free from the enterprise boundary, is adhered in a dimension of space economic system in a unique way. All the enterprises in such a space are an unavoidable and positive external existence. A correct recognition for the influence mechanism of enterprise endogenous innovation by the space economic system may also help enterprises to allocate internal and external innovation elements with a more scientific method and promote the innovation capacity.

\section{Literature Review}

Scholars have ever reviewed the innovation environment from different perspectives, differences in the innovation environment or space would inevitably exist. However, it is universally approved that, the interaction between the innovation elements and innovation conduct objects a necessary condition for the innovation development in the regional innovation system. 'Innovation is not an exclusive internal conduct taken by an enterprise to achieve the monopolistic advantage, but is an evolutionary and non-linear interactive 
process between the enterprise and environment' ${ }^{[1]}$. Based on dynamic feedback mechanism, Chesbrough (2003) put forward the concept of 'open innovation' ${ }^{[2]}$ to explore the dynamic mechanism of innovation expansion ${ }^{[3]}$.

The dynamic feedback between the enterprise and new environment can be achieved by knowledge transfer. The knowledge flow is identified as 'the transfer of knowledge between different subjects or the mechanism of knowledge processing' ${ }^{[4]}$ and 'the exchange process between the experience \& knowledge independently created by the organization with other organizations with the objective of realizing the expansion, accumulation and sharing of knowledge' ${ }^{[5]}$. Besides, it emphasizes that 'the movement process of knowledge when recognizing, obtaining, developing, resolving, storing, transferring, sharing, and utilizing its production value' ${ }^{[6]}$. It can be seen that, the knowledge flow should be included when delving into the reciprocal impacts between the enterprise innovation and innovation environment.

At present, most explorations on the relationship between the enterprise innovation and external environment have rested at the level of linear and static influence factors. However, few researches on the dynamic feedback mechanism are sufficiently delved into, and neither does the interaction mechanism from the perspective of the open innovation and knowledge flow. This paper took the 'knowledge flow' as an important dimension to delve into the dynamic feedback mechanism of the enterprise innovation and three-dimensional space and constituted and quantitatively demonstrated a systemic recognition of the three-dimensional space, knowledge flow and interaction mechanism of enterprise endogenous innovation under the perspective of open innovation.

\section{Constitutional Dimensions of Open Enterprise Innovation System}

Due to shocks from the non-competitive, non-exclusive and high- permeable "knowledge element", the strict enterprise boundary stressed by modern enterprise theory has been gradually weakened, leading to the openness in resources allocation of enterprise innovation. A rather complicated open innovation system has been formed by innovation elements between enterprises through the flow, expansion, penetration and transfer of knowledge. An open innovation system refers to the ordered collection of innovation elements under the specific time, space and industry standards, whose first dimension is spatial dimension, second dimension is knowledge flow dimension of innovation and third dimension is dimension of enterprise endogenous innovation. The enterprise boundary is clear (but not strict) in the dimension of enterprise endogenous innovation, in where the innovation may be completed. A three-dimensional space is the environment and space where enterprise innovation located. The interaction between the enterprise endogenous innovation and three-dimensional space of enterprise innovation could be achieved through the knowledge flow.

\subsection{Spatial Dimension}

Based on the space economic theory, the spatial dimension of enterprise innovation can be divided into three parts: loaded geographic spatial relationship provided for the resources exploitation and economic fields; an economic spatial relationship formed by economic activities of spatial entities; humanistic space relationship formed due to the interactions between spatial entities. They together restrict the density, mutual alignment and distribution pattern of innovation elements in innovation space. As a place for collecting innovation activities or a time-space dimension of innovation acts, the innovation three-dimensional space is an ordered recombination of the spatial system structure in innovation environment and a spatial system cored by creation, R \& D, learning, communication and other knowledge flows. 


\subsection{Endogenous Innovation Dimension}

The enterprise endogenous innovation acts based on an open perspective are endogenous, referring to an endogenous process of innovation elements allocation in the enterprise property right system. Its most notable feature is elements source in the process of an enterprises' innovation investment, wherein those innovation activities allocated by innovation elements of the enterprise may become the endogenous innovation. The endogenous system of enterprise innovation is the behavior system an enterprise built for carrying out the internal technical innovation activities by setting up the $R$ \& $D$ institutions, training R \& D teams, and boosting the investment of exploitation, whose core is the effective allocation of innovation elements (manpower, fund, information, management, etc.) in its property right boundary.

\subsection{Knowledge Flow Dimension}

The knowledge flow, referring to the process for accumulation, sharing and communication formed for value creation between knowledge stationary points as well as for knowledge fusion, ordering and innovation, is a systemic summary for the knowledge flow, transfer and innovation, etc. From the perspective of spatial dimension, it refers to the complicated internalization and externalization of knowledge existing between an enterprise and its space. On the one hand, the spatial knowledge is absorbed by the enterprise and thus internalized to its internal knowledge. On the other hand, the internal knowledge of an enterprise would also realize the externalization of knowledge through the knowledge flow.

\section{Overflow Mechanism and Conceptual Model of Knowledge Flow in the Open Enterprise Innovation System}

The property of free energy in the material system also applies to the innovation threedimensional spatial system ${ }^{[7]}$. The innovation three-dimensional spatial system could spontaneously tend to the direction of entropy maximization without any external force, make energy exchanges with another economic system and eventually tend to the dynamic balancing state. From the aspect of enterprise endogenous innovation, the internalization of knowledge flow tends to reduce the 'free energy' (spatial innovation knowledge) and enlarge 'knowledge entropy' in innovation three-dimensional space. The larger the 'free energy' in the innovation three-dimensional space is, the stronger the enterprise's innovation knowledge flow would be. If an enterprise could actively absorb and digest the 'free flow' (or knowledge flow) from the space, the internalization of knowledge flow would become stronger and the stock of internal innovation knowledge would be increased, vice versa. To be specific, with respect to the impacts on the enterprise exerted by the three-dimensional space, a single enterprise has a weaker overflow of reverse knowledge flow on innovation three-dimensional space, which cannot be easily estimated and observed. As a result, this paper may mainly delve into the positive overflow of knowledge flow of enterprise endogenous innovation by threedimensional space. The internalization and externalization process of knowledge existing between the innovation three-dimensional space and enterprise endogenous innovation would be eventually presented in a form of the dynamic equilibrium in system dynamics, as shown (e.g., Figure 1. 'Free Energy' Flow in the Innovation Three-Dimensional Space) 


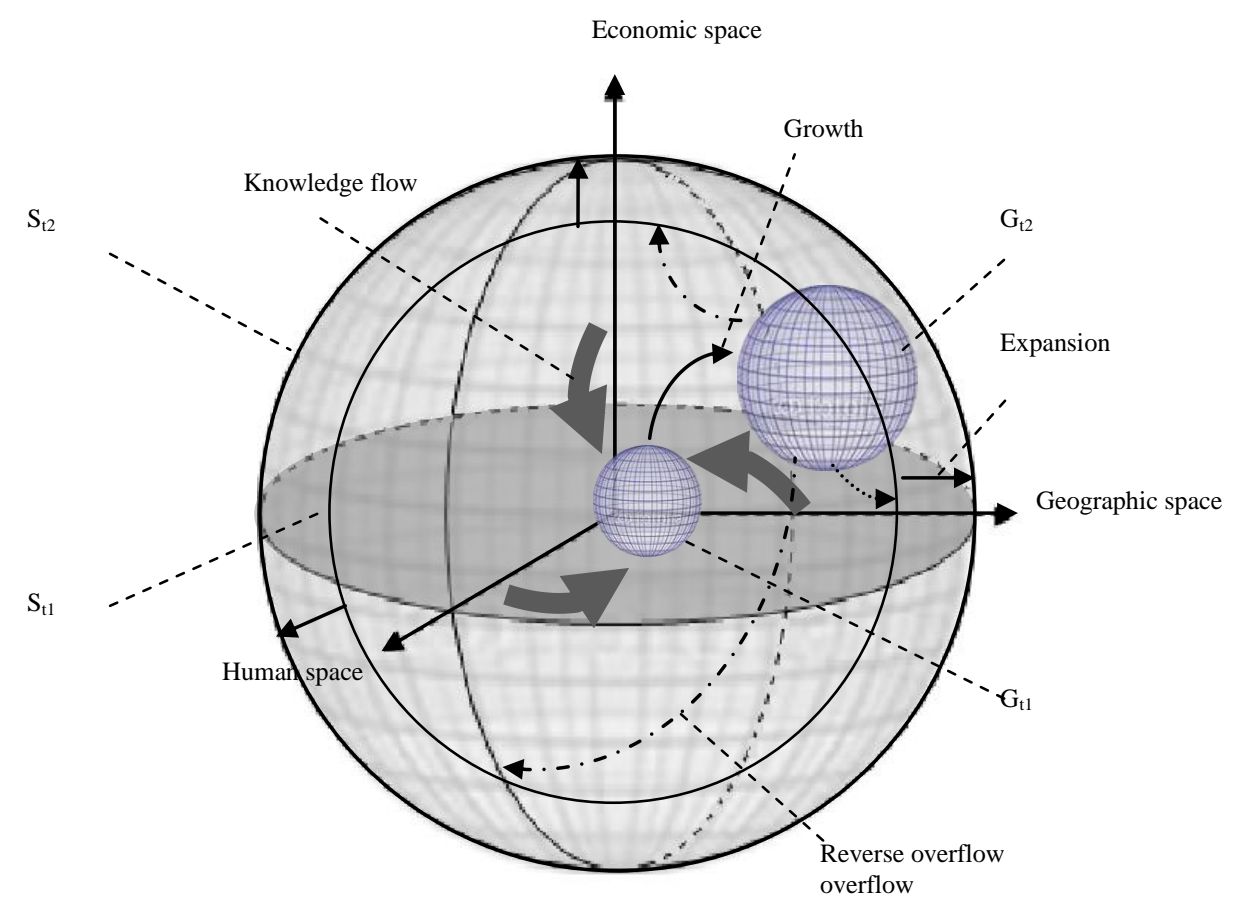

Figure 1. 'Free Energy' Flow in the Innovation Three-Dimensional Space

The innovation three-dimensional space, when overflowing the knowledge flow of the enterprise endogenous innovation, would also affected by other important variables of new fields in enterprise innovation, such as the intellectual properties protection, enterprises' absorptive capacity, industries involved and enterprise governance structure. Based on these, this paper set up a conceptual model for the overflow of knowledge flow in the open enterprise innovation system. As shown (e.g., Figure 2. the Conceptual Model for Overflow of Knowledge Flow)

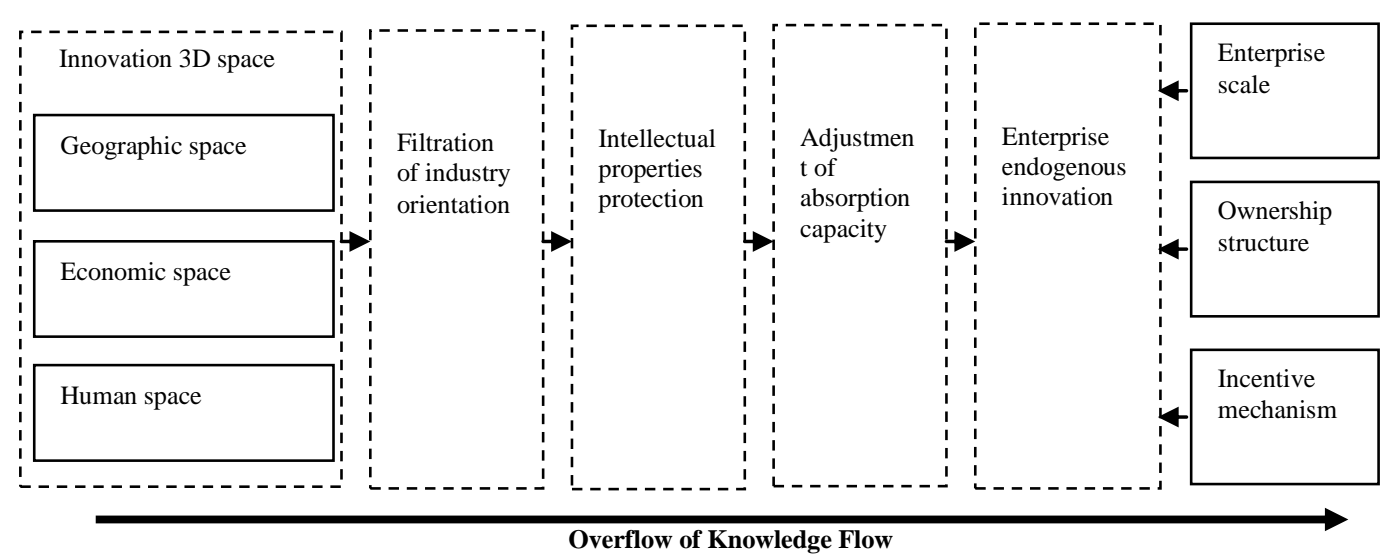

Figure 2. The Conceptual Model for Overflow of Knowledge Flow 


\section{Overflow Demonstration for Knowledge Flow on Enterprise Endogenous Innovation by the Three-Dimensional Space}

\subsection{Proposed Hypotheses}

The overflow mechanism in open enterprise innovation system indicated that, the innovation three-dimensional spatial system can make energy exchanges with another economic system without any external force. Besides, those innovation resources free from the property right boundary of an enterprise would be spontaneously or passively utilized by the enterprise and thus the enterprise's innovation efficiency and capacity would be promoted. Therefore, some hypotheses have been put forward as below:

H1: The innovation three-dimensional space promotes the enterprise endogenous innovation through the knowledge flow.

Before entering the enterprise, the innovation knowledge would be directionally filtered due to the existence of industry attributes. That innovation knowledge related to the industries the enterprise engaged on and those have nothing to do with the enterprise would not enter into the enterprise endogenous innovation system. Based on these, we further proposed the following hypotheses:

$\mathrm{H} 2$ : The industry attributes exert the effect of directional filtering for overflow of knowledge flow

H2a: For manufacturing enterprises, impacts on enterprise innovation exerted by innovation three-dimensional space are mainly determined by the geographical spatial units and less by economic spatial units.

$\mathrm{H} 2 \mathrm{~b}$ : For enterprises from service industry, impacts on enterprise innovation exerted by the innovation three-dimensional space are mainly determined by human spatial units and less by economic spatial units.

The knowledge overflow of enterprise endogenous innovation by three-dimensional space is conditional. The innovation knowledge output, formed by the innovation elements input of the enterprise, is the result the enterprise pursues for the exclusive competitive advantage as well. The power of protecting the overflow of innovation knowledge is a power an enterprise naturally provides. The property right protection of innovation three-dimensional space may be formed by adding up property right protections of single enterprises. The controls exerted on knowledge flow in the threedimensional space and knowledge flow of an enterprise by the property right protection are mutual or equivalent. Based on these, we further proposed the hypothesis below:

H3: The property right protection controls overflow of knowledge flow from the innovation three-dimensional space to the enterprise endogenous innovation.

The overflow effect of knowledge flow on the enterprise endogenous innovation exerted by three-dimensional space is adjusted by the enterprise's absorption capacity. If there's no such a strong absorption capacity of enterprise, the overflow of knowledge flow may merely stay at the theoretical level no matter how higher the potential energy of innovation knowledge in the three-dimensional space. Again, the overflow of knowledge flow would be directionally filtered by the enterprise's absorption capacity. No all of the overflowing knowledge can be internalized into the enterprise's innovation capacity, only those adhering to the enterprise's innovation strategic direction could be absorbed. Based on this, we proposed the following hypothesis: 
H4: The enterprise's absorption capacity promotes the overflow of knowledge flow from the innovation three-dimensional space to the enterprise endogenous innovation.

The relationship between the technical innovation and enterprise scale is a very controversial problem in the field of innovation researches, wherein the linear relationship represented by 'Schumpeterian Hypothesis' and non-linear relationship represented by reverse U relation is a focus of controversy. 'Schumpeterian Hypothesis' holds that, larger enterprise scale may be conductive to the technical innovation, which has been supported by Galbraith (1952) ${ }^{[8]}$ and Villard (1958) ${ }^{[9]}$ et al. However, Worley (1961) ${ }^{[10]}$, Mansfield (1968), Jaffe (1988) ${ }^{[11]}$ et al have drawn different conclusions. Limited by a smaller available innovation resources, the absolute innovation output in small enterprises would be relatively small. A larger enterprise scale may contribute to a larger innovation investment and higher absolute output of natural innovation. Nevertheless, the innovation follows the law of scale remuneration decreasing as the production does. Hence, when the enterprise innovation scale reaches up a certain extent, the innovation efficiency would be relatively low. As a consequence, we took the enterprise scale as a control variable in enterprise endogenous innovation and proposed the following hypothesis:

H5: Through the impact on the enterprise endogenous innovation exerted by the knowledge flow, the innovation three-dimensional space is controlled by the enterprise scale. The larger the enterprise scale is, the more significant impact would be.

Delving into the enterprise's innovation conducts from the aspect of equity concentration is another focus by scholars. Baysinger (1991) and et al hold that, the positive correlation of equity concentration and business $R \& D$ expenditure may promote the enterprise innovation ${ }^{[12]}$. Hill and Snell (1998) delved into the relationship between the equity concentration and $R \& D$ strength and obtained the conclusion of positive correlation ${ }^{[13]}$. By the positive analysis of Japanese manufacturing industries, Hosono, Tomiyama and Miyagawa (2004) obtained a conclusion that the shareholding ratio and ratio of liabilities to assets of major shareholders has a positive impact on R\&D strength ${ }^{[14]}$. Hence, this paper took the equity concentration of an enterprise as a control variable of enterprise and proposed the following hypothesis:

H6: The innovation three-dimensional space is controlled by the equity concentration of an enterprise through the impacts on enterprise endogenous innovation by the knowledge flow and higher concentration means a more significant impact.

Behaviorism believes that the expected innovation behaviors could be achieved by providing the compensation in a systematic way ${ }^{[15][16]}$. External motivation is an essential condition to motivate personnel for innovation ${ }^{[17]}$. The expected wage increase and monetary award that are linked to the performance has a positive impact on the innovation acts and performances of personnel ${ }^{[18]}$. As an important means the organization takes to motivate the personnel in a context of social exchanges, the performance salary exerts a direct or indirect impact on the personnel conducts ${ }^{[19]}$. Therefore, we took the enterprise compensation as a control variable of the enterprise endogenous innovation and proposed the following hypothesis:

H7: The innovation three-dimensional space is controlled by the average compensation of an enterprise through the impacts on enterprise endogenous innovation by the knowledge flow, and higher average compensation of an enterprise means a more significant impact. 


\subsection{Samples, Variables and Data}

Under the condition of available data, this paper extracted 355 Chinese listed companies on GEM and revolved 27 provinces as of November 2013 as analysis samples, and selected the structural equation model (SEM) to make the demonstration examination of an interrelation between the innovation three-dimensional space, knowledge flow and enterprise endogenous innovation. The variables system can be seen (e.g., Table 1. Variable System). With regard to data processing, this paper conducted the exploratory factor analysis by directly observing indexes, established an innovation three-dimensional space, made the indirect observation of variables of enterprise innovation efficiency and knowledge flow, and determined index weights and weighting for acquiring data. The property right protection of three-dimensional space is established by the superposition of property right protection measures (number of patents owned by enterprise). This paper followed the metric scheme conducted by Zahra and George (2002), used factor analysis method, extracted common factors of 'recognition of new knowledge', 'absorption of new knowledge' and 'application of new knowledge', as well as collected the absorption capacity variables of an enterprise.

This paper used SPSS19.0 software to achieve the data analysis of variables and found out that the variables for understanding the cognitive attitude of various influencing factors are provided with a higher reliability. A confirmatory factor analysis for the explanatory variables, explained variables, intervening variables and controlled variables was made. Judging from $t$ rule, all variables satisfy: $t<q \cdot(q+1) / 2$, meaning that they all can be recognized and provided with a better fitting degree in the fitness degree of total model. The construct reliability of latent variables can be accepted.

Table 1. Variable System

\begin{tabular}{|c|c|c|c|}
\hline & $\begin{array}{l}\text { Latent } \\
\text { Varia- } \\
\text { ble }\end{array}$ & $\begin{array}{l}\text { Indirect } \\
\text { Observed } \\
\text { Variable }\end{array}$ & Direct Observed Variable \\
\hline \multirow[t]{2}{*}{ 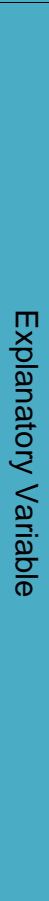 } & 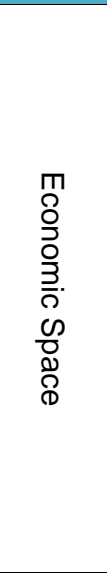 & $\begin{array}{l}\text { Economic } \\
\text { Structure (A1) } \\
\text { Economic } \\
\text { Vitality (A2) } \\
\text { Economic } \\
\text { Scale (A3) }\end{array}$ & $\begin{array}{l}\text {-Regional Economic Development Potential (GDP Growth } \\
\text { Rate) } \\
\text {-Regional Economic Openness } \\
\text {-Energy Consumption Per Unit GDP } \\
\text {-Regional Sales Revenue of New Products } \\
\text {-Proportion of GDP by Industrial Output of } \\
\text { - New And High Technology Industries } \\
\text {-Proportion of GDP by Regional Social Fixed } \\
\text {-Assets Investment } \\
\text {-Proportion of GDP by Regional Actual Used } \\
\text {-Foreign Investment } \\
\text {-Proportion of GDP by Regional Gross Social } \\
\text {-Retail Goods } \\
\text {-Per Capital Gross Regional Product } \\
\text {-Ratio of Regional Second and Third Industry }\end{array}$ \\
\hline & 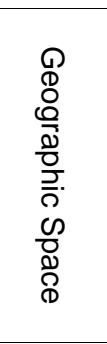 & $\begin{array}{l}\text { Geographical } \\
\text { Structure (A4) } \\
\text { Resource } \\
\text { Environment } \\
\text { (A5) }\end{array}$ & $\begin{array}{l}\text {-Region Urbanization Development Level (Proportion of Urban } \\
\text { Residents) } \\
\text {-Regional Geographical Location Advantage (Determined by } \\
\text { the Expert Scoring) } \\
\text {-Regional Natural Environment of Human Settlement (Person/ } \\
\text { Square Kilometer) } \\
\text {-Regional Resource Abundance Degree (Determined by the } \\
\text { Expert Scoring) } \\
\text { 'Length of Long-Distance Optical Cable Line }\end{array}$ \\
\hline
\end{tabular}




\begin{tabular}{|c|c|c|c|}
\hline & 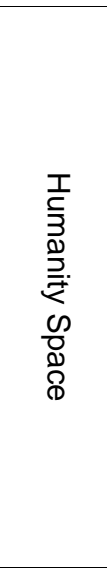 & $\begin{array}{l}\text { Cultural } \\
\text { Environment } \\
\text { (A6) } \\
\text { Policy } \\
\text { Environment } \\
\text { (A7) } \\
\text { Legal } \\
\text { Environment } \\
\text { (A8) }\end{array}$ & $\begin{array}{l}\text {-Average Number of Students at School Per Regional 100,000 } \\
\text { Persons } \\
\text {-Total Per Capita Number of Printed Regional Books, Journals } \\
\text { and Newspapers } \\
\text {-Number of Domestic Patent Applications and Authorizations } \\
\text {-Full-Time Equivalent of R\&D Personnel } \\
\text {-Proportion of GDP by Regional Science and } \\
\text {-Technology Spending } \\
\text {-Researcher Fellows in Public Economic Enterprises in 10,000 } \\
\text { Persons } \\
\text {-Proportion of GDP by Regional General Public Service } \\
\text { Expenditure } \\
\text {-Cases Accepted by Procuratorial Organ of Thousand Persons } \\
\text {-Crime Rate } \\
\text {-Number of Lawyers }\end{array}$ \\
\hline \multirow{2}{*}{ 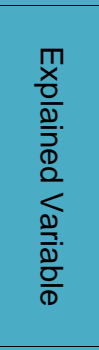 } & \multirow{2}{*}{ 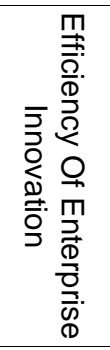 } & $\begin{array}{l}\text { Technical } \\
\text { Efficiency (A9) }\end{array}$ & $\begin{array}{l}\text {-Proportion of Operation Revenue by R\&D Expenditures } \\
\text {-Proportion of Total Personnel by R\&D Talents } \\
\text {-Intangible Assets } \\
\text {-Number of Owned Patents }\end{array}$ \\
\hline & & $\begin{array}{l}\text { Competitive } \\
\text { Efficiency } \\
\text { (A10) }\end{array}$ & $\begin{array}{l}\text {-Average Operating Cost in Past Three Years } \\
\text { Total Number of Employees } \\
\text {-Average Total Profit in Past Three Years } \\
\text {-Sustainable Growth Rate of the Company } \\
\text {-Towbin Q Value }\end{array}$ \\
\hline 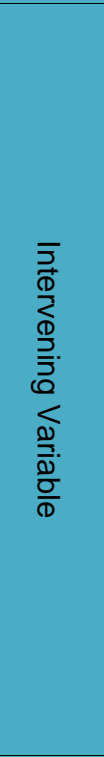 & 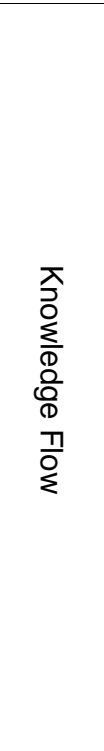 & $\begin{array}{l}\text { Technology } \\
\text { Flow (A11) } \\
\text { Talent Flow } \\
\text { (A12) } \\
\text { Information } \\
\text { Flow (A13) } \\
\text { Commodity } \\
\text { Flow (A14) }\end{array}$ & $\begin{array}{l}\text {-Per Capita Domestic Technology Spending } \\
\text {-Per Capita Foreign Technology Introduced Contract Amount } \\
\text {-Per Capita Volume of Transaction in the Technology Market } \\
\text {-Number of Authorized Patents in Ten Thousand Persons } \\
\text {-Total Per Capita Number of Printed } \\
\text {-Newspapers, Journals and Books } \\
\text {-Number of Per Capita Webpages } \\
\text {-Number of Per Capita Internet Users } \\
\text {-Length of Ten-Thousand Optical Cable Line } \\
\text {-Proportion of Employed Person of Graduate or Above } \\
\text {-Total Proportion of Research Fellows } \\
\text {-Number of Master's Degree Awarded to the In-Service } \\
\text { Personnel } \\
\text {-Proportion of Senior Full-Time Teachers in } \\
\text {-Regular Institutions of Higher Education } \\
\text {-Per Capita Software Business Income } \\
\text {-Per Capita Sales Income of New Products in Industrial } \\
\text { Enterprises above Designated Size } \\
\text {-Number of New Products in Industrial Enterprises Above } \\
100,000 \text { Persons }\end{array}$ \\
\hline \multirow[t]{2}{*}{$\begin{array}{l}\text { Contr } \\
\text { ol } \\
\text { Varia } \\
\text { ble }\end{array}$} & $\begin{array}{l}\cdot \text {-Absorp } \\
\cdot \text { - Proper } \\
\cdot \text {-Enterp } \\
\text { - Owner } \\
\text { - Compe }\end{array}$ & $\begin{array}{l}\text { n Capacity (A15) } \\
\text { Right Protection } \\
\text { e Scale (Total As } \\
\text { ip Structure (Equ } \\
\text { sation Incentives }\end{array}$ & $\begin{array}{l}\text { A16) } \\
\text { sets of the Enterprise) (A17) } \\
\text { ty Concentration) (A18) } \\
\text { Compensation Growth Rate) (A19) }\end{array}$ \\
\hline & \multicolumn{3}{|c|}{ · Industry Attributes (A20) } \\
\hline
\end{tabular}

Data Source : National Database of China; Statistical Yearbook of Each Province; RESSET Statistical Database; CCERb; CPRS; Annual Reports of Listed Companies on GEM; China Statistical Yearbook on Science and Technology; Expert Scoring.

\subsection{Model Construction and Hypothesis Testing}

In order to explore the overflow effect of knowledge flow from innovation threedimensional space to the enterprise endogenous innovation, this paper used AMOS7.0 software to set up the structural equation simulation for the manufacturing industry and 
industry, respectively. As shown (e.g., Figure 3. SEM for Overflow of Knowledge Flow)

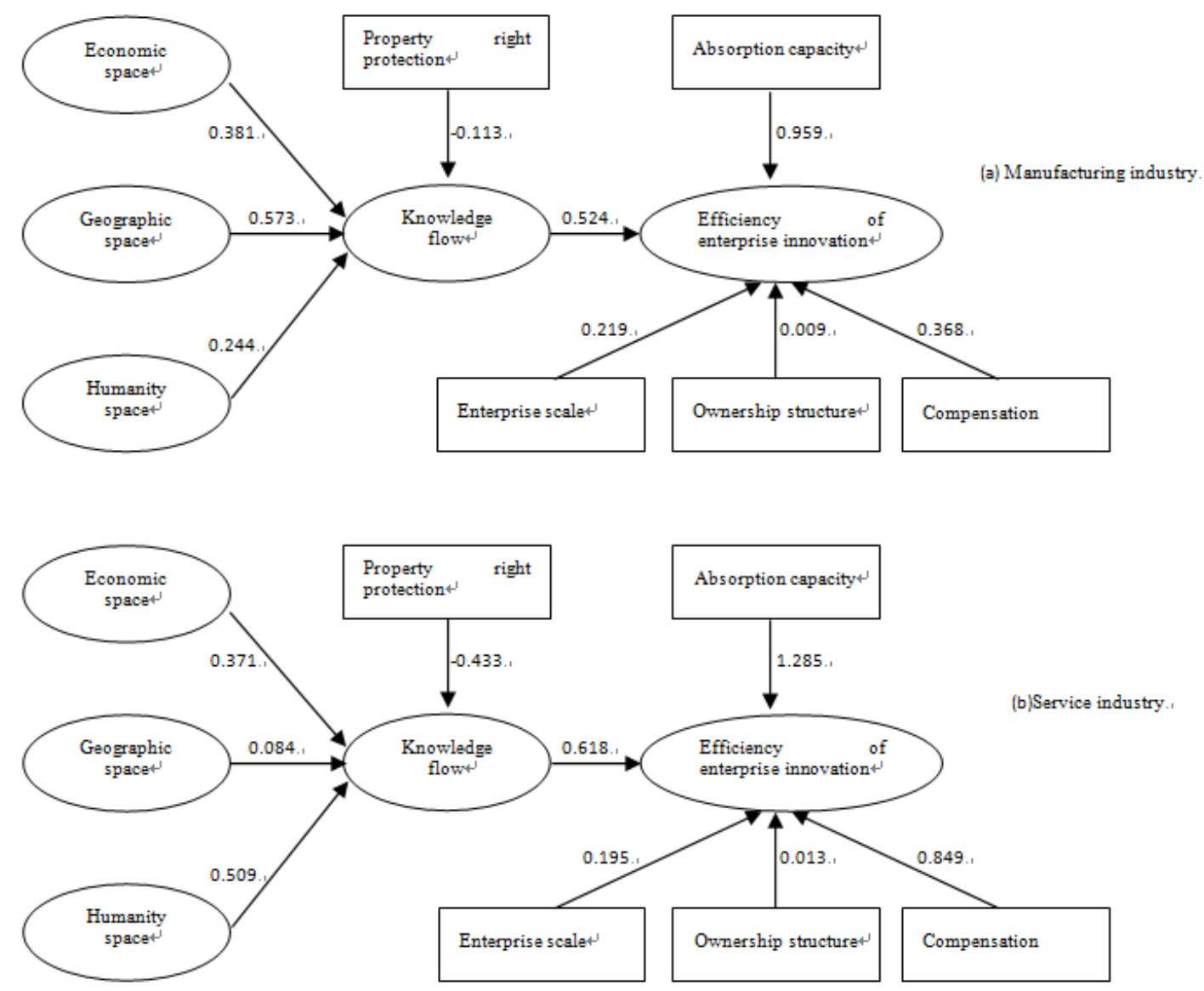

Figure 3. SEM for Overflow of Knowledge Flow

The path coefficients of knowledge flow by economic space, geographic space and humanity space in the innovation three-dimensional space in the manufacturing industry are $0.381,0.573$ and 0.244 , respectively. But in the service industry, path coefficients are $0.371,0.084$ and 0.509 , respectively. based on the data from the manufacturing industry and service industry, the path coefficients on the efficiency of enterprise innovation of knowledge flow are 0.424 and 0.618 , respectively. And both of them have obvious statistical significance and economic significance in the confidence interval of $p<0.05$. Therefore, $\mathrm{H} 1$ is correct, no matter the manufacturing industry or the service industry, the economic space, geographic space and humanity space have exerted a positive promoting effect on the efficiency of enterprise innovation by the knowledge flow.

The impacts exerted by humanity space are smaller and impacts exerted by geographic space are larger in the manufacturing industry, while in the service industry, the contrary is the case. Hence, $\mathrm{H} 2$ is correct: industry attribute have the directional filtering function for the overflow of knowledge flow. For enterprises in the manufacturing industry, impacts on enterprise innovation by innovation three-dimensional space are mainly determined by geographical spatial units and less by economic spatial units. However, for enterprises in the service industry, impacts are mainly determined by the humanity spatial units and less by economic spatial units. 
In the case of the manufacturing industry and service industry, path coefficients of knowledge flow by the intellectual property protection are -0.113 and -0.433 , respectively. Because the intellectual property protection has an inhibiting effect on the overflow of knowledge flow from the innovation three-dimensional space to enterprise endogenous innovation, $\mathrm{H} 3$ is correct. The path coefficients of enterprise endogenous innovation by the absorption capacity are 0.959 and 1.285 , respectively, which may promote the overflow of knowledge flow from the innovation three-dimensional space to enterprise endogenous innovation, so $\mathrm{H} 4$ is correct.

The path coefficients of enterprise innovation efficiency by enterprise scale, equity concentration and compensation incentive in the manufacturing industry are $0.219,0.009$ and 0.368 , respectively. The path coefficients of enterprise innovation efficiency by enterprise scale, equity concentration and compensation incentive in the manufacturing industry are $0.195,0.013$ and 0.849 , respectively. It follows that, the innovation threedimensional space is controlled by the enterprise scale through the impacts on enterprise endogenous innovation by knowledge flow, wherein a larger scale means a more significant impact, so H5 is correct. The innovation three-dimensional space is controlled by the enterprise's average compensation through the impacts on enterprise endogenous innovation by knowledge flow, wherein a higher average compensation means a more significant impact, so H7 is correct. The innovation three-dimensional space is controlled by the equity concentration of an enterprise through impacts on enterprise endogenous innovation by knowledge flow, wherein the impacts are not significant, so H6 is not correct. The reason may be that, for different industries, the innovation input and output patterns and impacts on innovation by equity concentration may be different. And at last, the impacts on the enterprise endogenous innovation by equity concentration may not be so significant.

The empirical results demonstrated that, the analyses and hypotheses on the overflow mechanism and demonstration of knowledge flow on enterprise endogenous innovation by three-dimensional space based on the open innovation perspective proposed in this paper are reasonable.

\section{Research Conclusions}

This paper introduced the concept of knowledge flow under an open innovation perspective, delved into the evolution mechanism of three-dimensional space and enterprise endogenous innovation, used the structural equation model for demonstration, and thus obtained the following conclusions:

(1) The three-dimensional space of enterprise innovation is jointly constituted by economic space, geographic space and humanity space form, characterized in systematicness, stability, polarization, diffusivity and orderliness. At the same time, it is a space of knowledge flow outside the enterprise as well.

(2) In the open innovation system, the non-rigid boundary of enterprises provides the possibility for the overflow, expansion and penetration of external knowledge. The original power of enterprise innovation is still from the normal operation of enterprise endogenous innovation. The innovation three-dimensional space exerts a control and condition effect of enterprise endogenous innovation. The interaction between enterprise endogenous innovation and innovation three-dimensional space is achieved through the mediation of knowledge flow.

(3) The larger 'free energy' in the innovation three-dimensional space is, the stronger enterprise innovation knowledge flow would be. If an enterprise can actively absorb and digest the 'free flow' (or knowledge flow) from the space, the internalization of knowledge flow may become stronger and the stock of internal innovation knowledge would be increased. The enterprises in the space are provided with the possibility of 
releasing the 'free flow' to the space, which is the externalization process of knowledge from the enterprise system to the space. The whole process would not finish as soon as the first overflow is done, but form a dynamic balance. The knowledge internalization and externalization between the innovation three-dimensional space and the enterprise endogenous innovation may be presented by the dynamic balance of system dynamics.

\section{Acknowledgments}

This work was financially supported by National Natural Science Foundation of China (NSFC) (71562004).

\section{References}

[1] S. J. Kline and N. Rosenberg, "An Overview of Innovation", in R. Laudan and N. Rosenberg (eds), The Positive Sum Strategy, Harnessing Technology for Economics Growth, Washington DC: National Academy Press, (1986), pp. 78-79.

[2] H. W. Chesbrough, "The era of open innovation", MIT Sloan Management Review, vol. 13, no. 44, (2003), pp. 35-41.

[3] Lichtenthaler, "Open innovation: past research, current debates, and future directions", Academy of Management Perspectives, vol. 18, no.7, (2011), pp. 75-93.

[4] H. Zhuge, "A Knowledge Flow Model for Peer-to-peer Team Knowledge Sharing and Management", Expert Systems with Applications, vol. 23, no. 1, (2002), pp. 23-30.

[5] S.-C.Fang, J. L. Lin and L. Y. C. Hsiao, "The Relationship of R\&D Units in Taiwan and Taiwanese Knowledge Flow System", Technovation, vol. 24, no. 6, (2002), pp. 371-383.

[6] J. Wang, J. Wu and Q. Zhang, "Research on the Relationship between Knowledge Flow, Knowledge Innovation and Dynamic Capacity Based on Competition Advantages", Journal of Information, vol. 22, no. 2, (2002), pp. 144-147.

[7] Z. Chen and M. Rui, "Analysis for Sources of Enterprise Competition Advantages: Used Value of Dynamic Property in Equal Production Elements", Economists, vol. 18, no.4, (2006), pp. 70-77.

[8] J. K. Galbraith, "American Capitalism: The Concept of Countervailing Power", Boston: Houghton Mifflin, (1952), pp. 119-121.

[9] H. H. Villard, "Competition, Oligopoly, and Research", Journal of Political Economy, vol. 66, no. 6, (1958), pp. 483-497.

[10] J. S. Worley, "Industrial Research and the New Competition", Journal of Political Economy, vol. 69, no.7, (1961), pp. 183-86.

[11] A. B. Jaffe, "Demand and Supply Influences in R\&D Intensity and Productivity Growth", Review of Economics and Statistics, vol. 70, no. 3, (1988), pp. 431-437.

[12] B. D. Baysinger, R. D. Kosnika and T. A. Turk, "Effects of Board and Ownership Structure on Corporate R\& D Strategy", Academy of Management Journal, vol. 34, no. 1, (2006), pp. 205-214.

[13] C. W. L. Hill and S. A. Snell, "External control, corporate strategy and firm performance in research intensive industries", Strategic Management Journal, vol. 44, no. 9, (1988), pp. 577-590.

[14] K. Hosono, M. Tomiyama and T. Miyagawa, "Corporate governance and research and development: Evidence from Japan”, Economic Innovation New Technology, vol. 27, no. 13, (2004), pp. 141-164.

[15] A. S. Winston and J. E. Baker, "Behavior Analytic Studies of Creativity: A Critical Review", The Behavior Analyst, vol. 23, no. 8, (1985), pp. 191-205.

[16] M. R. Edwards, "Measuring Creativity at Work: Developing A Reward-for-creativity Policy", Journal of Creative Behavior, vol. 31, no. 23, (1989), pp. 26-37.

[17] T. M. Amabile, B. A. Hennessey and B. S. Grossman, "Social Influences on Creativity: the Effects of Contracted for Reward", Journal of Personality and Social Psychology, vol. 31, no.50, (1986), pp. 14-23.

[18] R. Eisenberger, F. Haskins and P. Gambleton, "Promised Reward and Creativity: Effects of Prior Experience”, Journal of Experimental Social Psychology, vol. 21, no.35, (1999), pp. 308-325.

[19] B. Gerhart, S. L. Rynes and I. S. Fulmer, "Pay and Performance: Individuals, Groups, and Executives", The Academy of Management Annals, vol. 3, no. 1, (2009), pp. 251-315.

[20] M. Yang and Z. Chen, "Comparable Measurement for Efficiency of Enterprise Innovation in Competitive Industries: Based on DEA Twice Superposition of Extreme Simulation", Soft Science, vol. 29, no. 7, (2015), pp. 7-12. 
International Journal of Security and Its Applications

Vol. 10, No. 3 (2016) 